\title{
UMA POESIA, MEU LUGAR!
}

Maria do Socorro Braga Reis ${ }^{1}$

Apeú - Salvador ${ }^{2}$ é ilha beijada pelo Atlântico, lugar de muitas lendas. A sua concepção ainda é um mistério. Muitos contam da chegada do Capitão Ulisses, outros afirmam que foi lugar escolhido por negros para se esconderem da escravidão, outros, ainda, dizem que aqui era morada de índios. Mas a verdade é que não sabemos ao certo quando tudo começou. Sabemos apenas que aqui todas as cores e raças se misturam irmanadas pelo Amor que nos une a todos.

Ilha Farta e Receptiva é assim que a denomino. Todos que aqui chegam são amparados e nada lhe faltam. Nada nos falta. A minha rotina é olhar a imensidão das águas que vão e que vem, que nos ditam as horas de pescar, de colher, de comer... Amanheço o dia: hora de pegar água, molhar as plantas, e rezar, olhar as crianças, que brincam na areia, misturadas aos animais, em uma relação tão intensa e igualitária com a natureza. Ah, como são sábias, elas.

E se há alguma coisa que sinto falta nessa ilha é de uma mangueira, imponente que tinha na beira do porto, linda e majestosa. Nela havia um quê de encanto. Parecia eterna. E seus frutos eram tão necessários para aqueles que iam pegar o sustento, mas o mar, lá, é mais imponente que qualquer outro fenômeno da natureza, e a levou, a quis para si, e a levou, ficando apenas a saudade de sua sombra em tempos tão quentes e de seus frutos tão apreciados.

As crenças vão além do sagrado, no meu lugar encantado. Quase tudo é permitido, desde que se respeitem as tradições; as plantas tem um lugar especial em nossos terreiros, e são bem cuidadas, porque a qualquer hora podem ser evocadas para curar algum mal, até mesmo o mau-olhado. Cabem a nossas mãos enrugadas a tarefa de trazer ao mundo a canalha ${ }^{3}$ que enfeita a praia.

No cotidiano vejo a vida passar, algumas lembranças, maré que nos empurra, diminuindo o nosso território, a saudade dos que se foram pela maré dos tempos... Alegria com os que chegam! Como o meu coração fica eufórico em ver uma casa sendo construída, pois é sinal que não iremos desaparecer. A praia é o meu lugar, é o meu porto, é a minha vida,

\footnotetext{
${ }^{1}$ Mestranda do Programa de Pós-Graduação em Linguagens e Saberes da Amazônia, UFPA - Campus Bragança. E-mail: msocorrobraga@yahoo.com.br.

${ }^{2}$ Praia de Apéu - Salvador está situada no município de Viseu nos estuários dos rios Gurupi e Piriá, no Oceano Atlântico.

${ }^{3}$ Denominação a crianças e aos adolescentes.
} 
nosso alimento é saudável: camarão, peixe, e as frutas. Delas, a que eu mais gosto é guajiru, sobretudo do doce de guajiru, frutinha cuidada pelos nossos encantados.

A poesia está presente no mais lindo pôr do sol, o qual todos os dias eu espero vê-lo deitar, e é mágico! É impressionante a sua elegância, e muito mais deslumbrante quando se vai e deixa a sua amada lua para brilhar nas palhas de coqueiros que o vento teima em farfalhar.

São coisas simples, de gente simples como eu que passo horas a carregar/ver água, para manter o frescor das plantas, da vida, e do amor pela vida. Ah, eu tenho um caso de amor com meu lugar! O mais rico legado deixado a cada um que coloquei no mundo. O Amor pela nossa praia, a praia de Apeú de São Salvador!

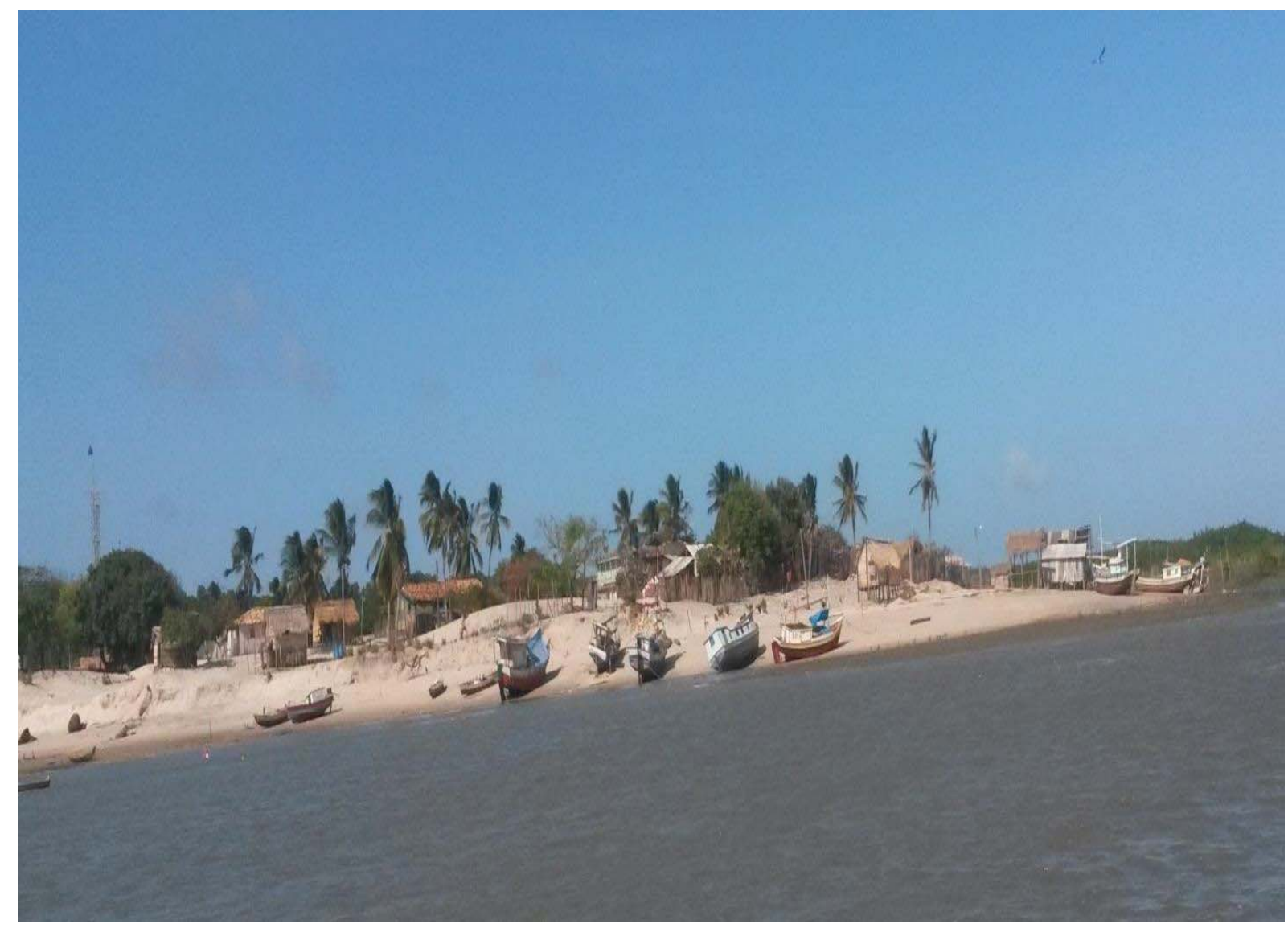



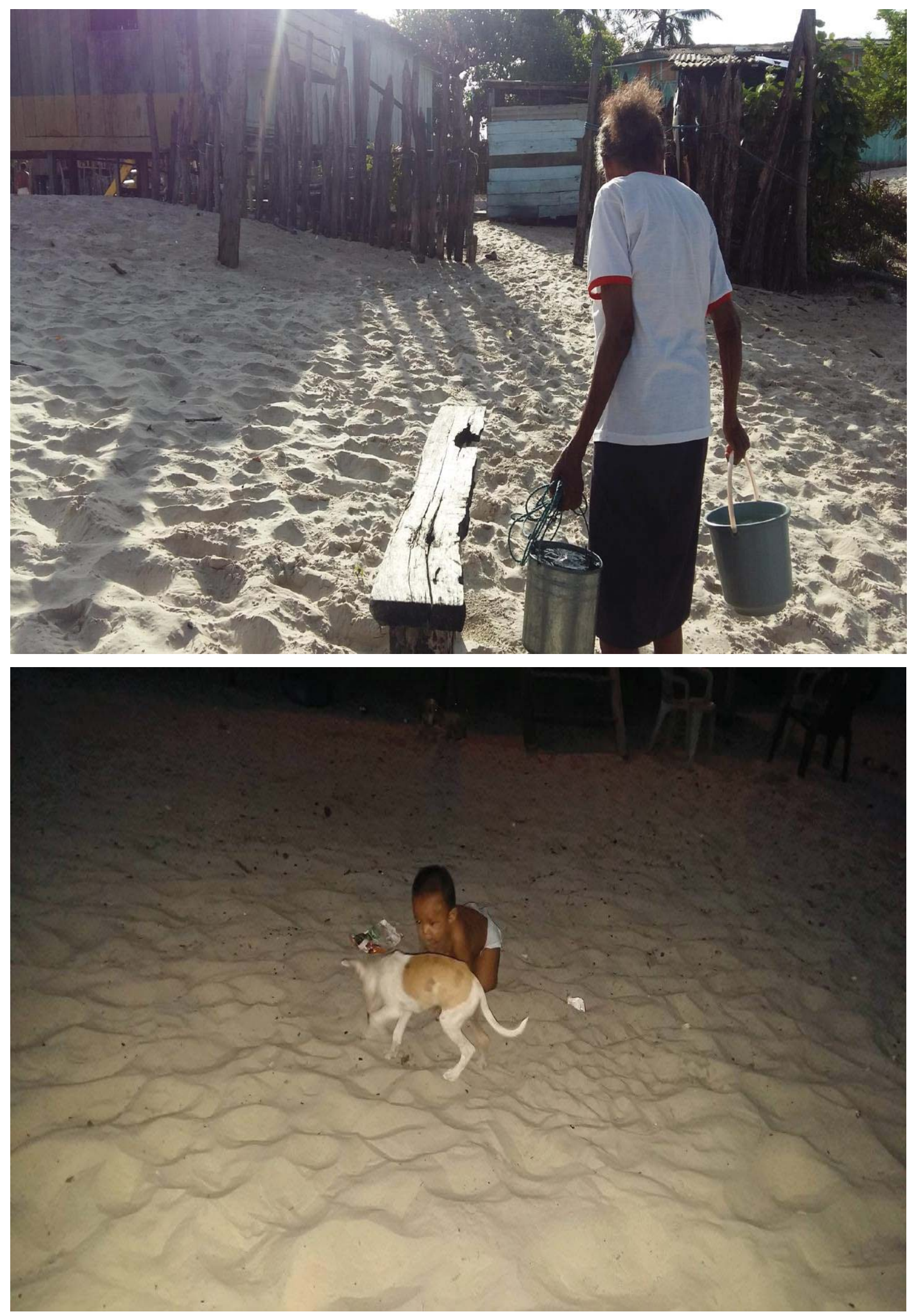


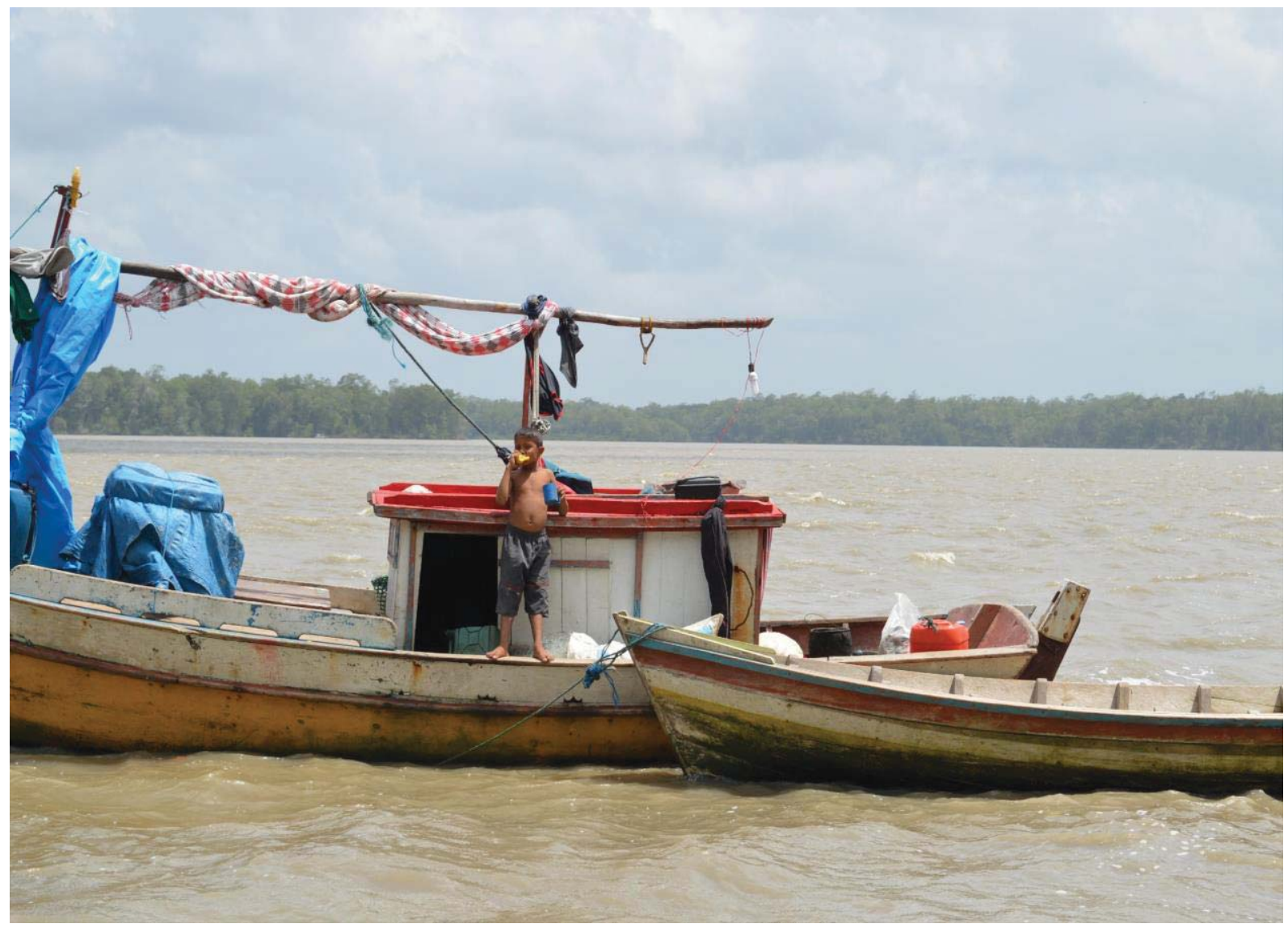



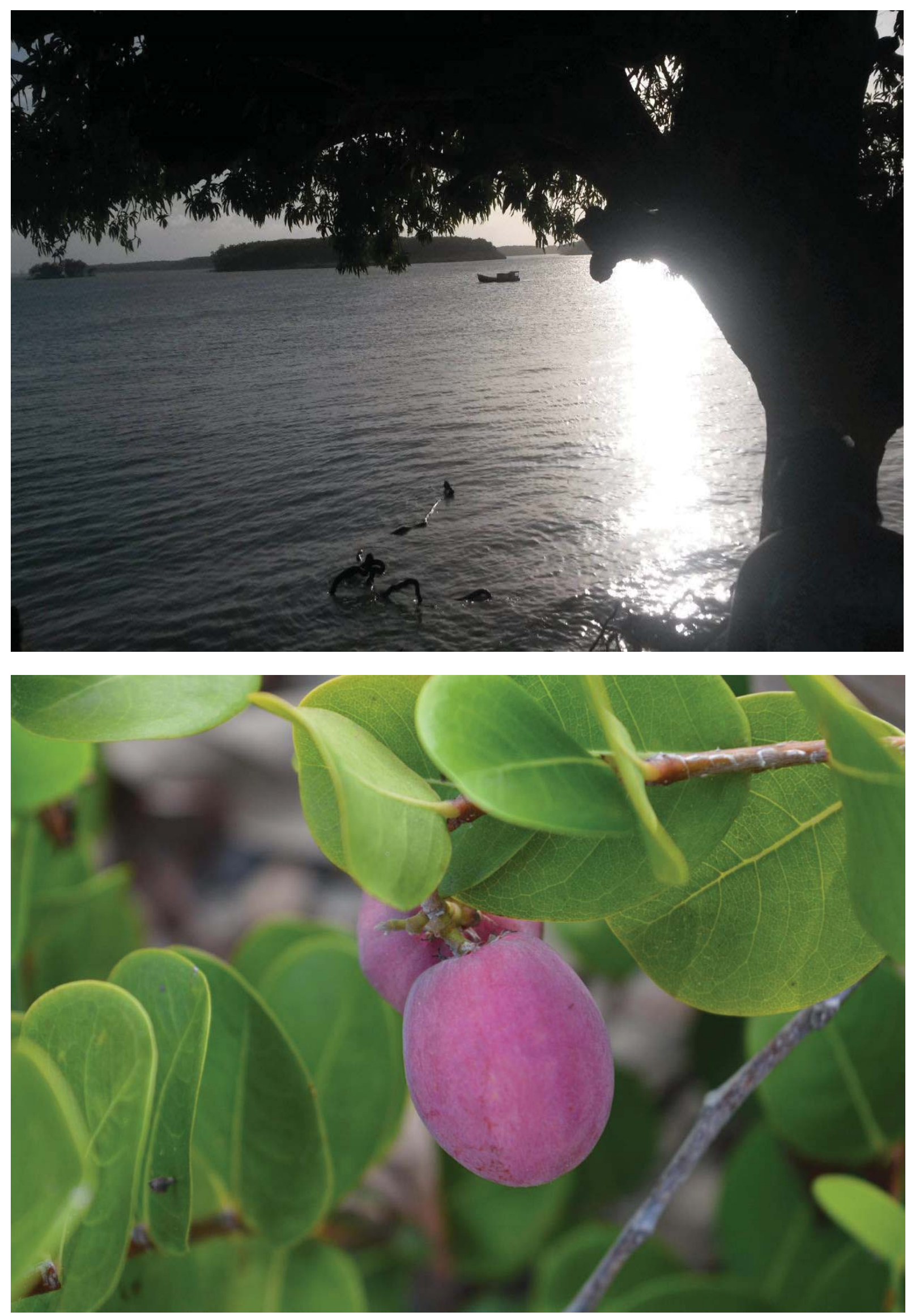


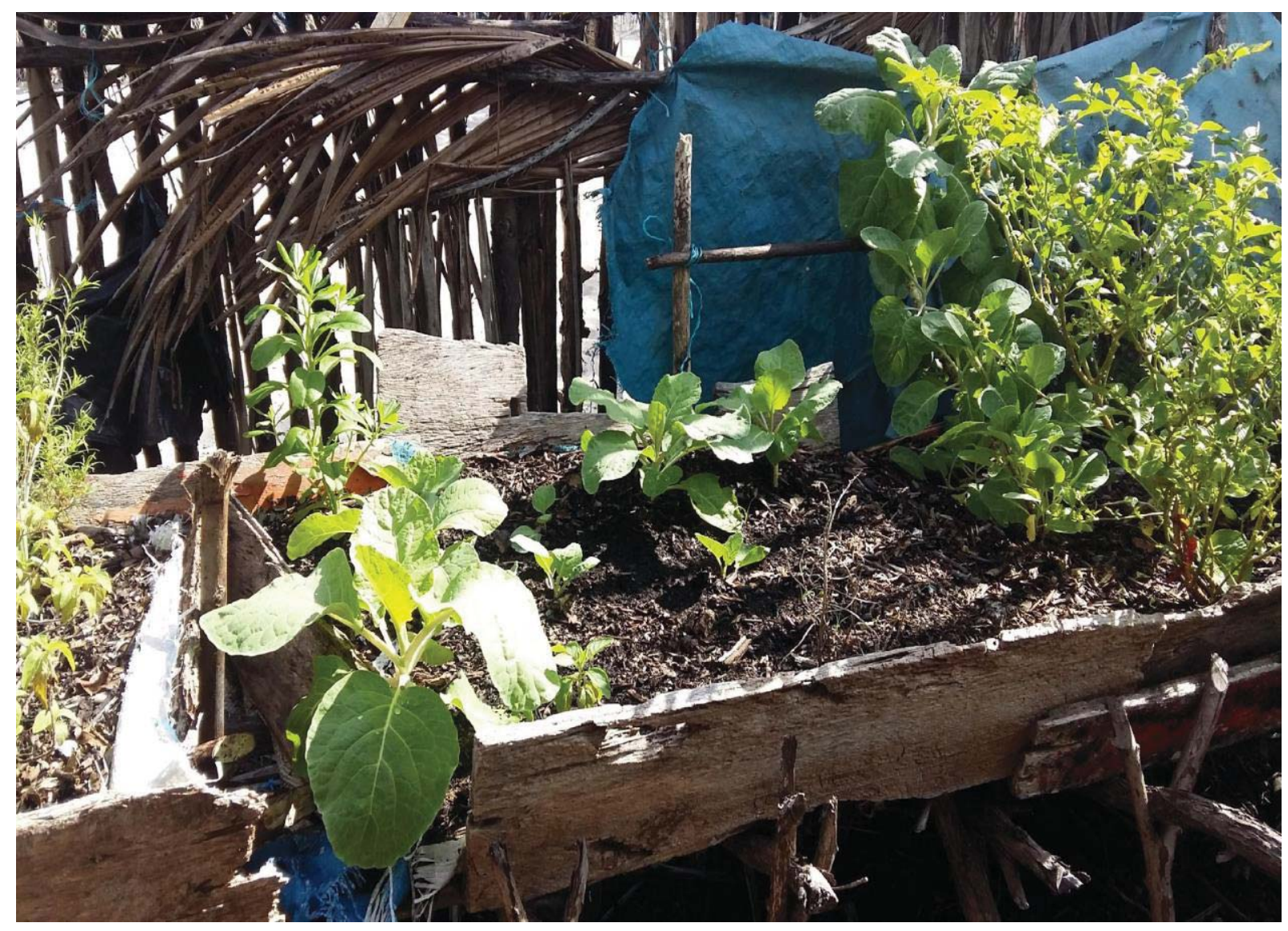




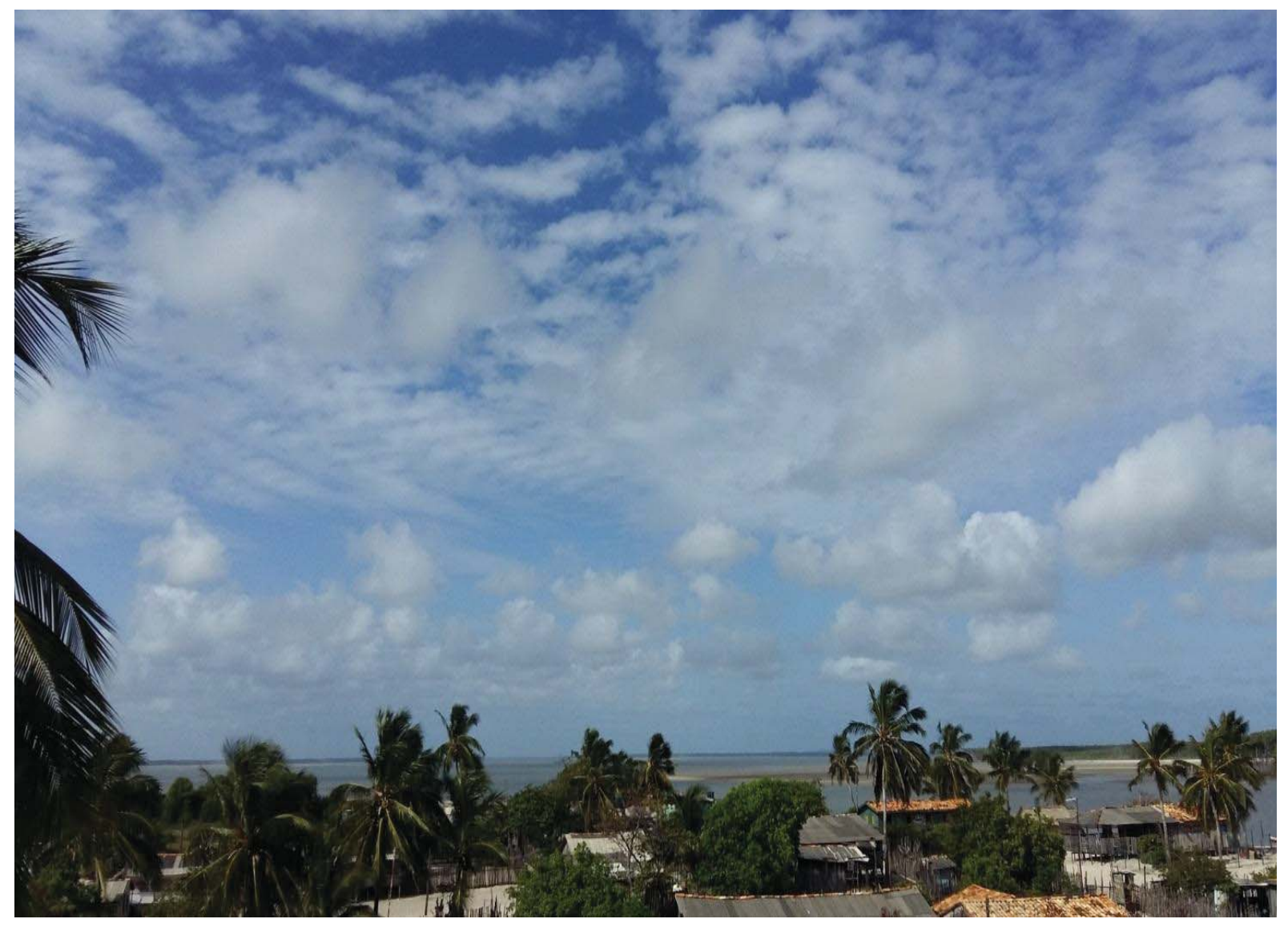




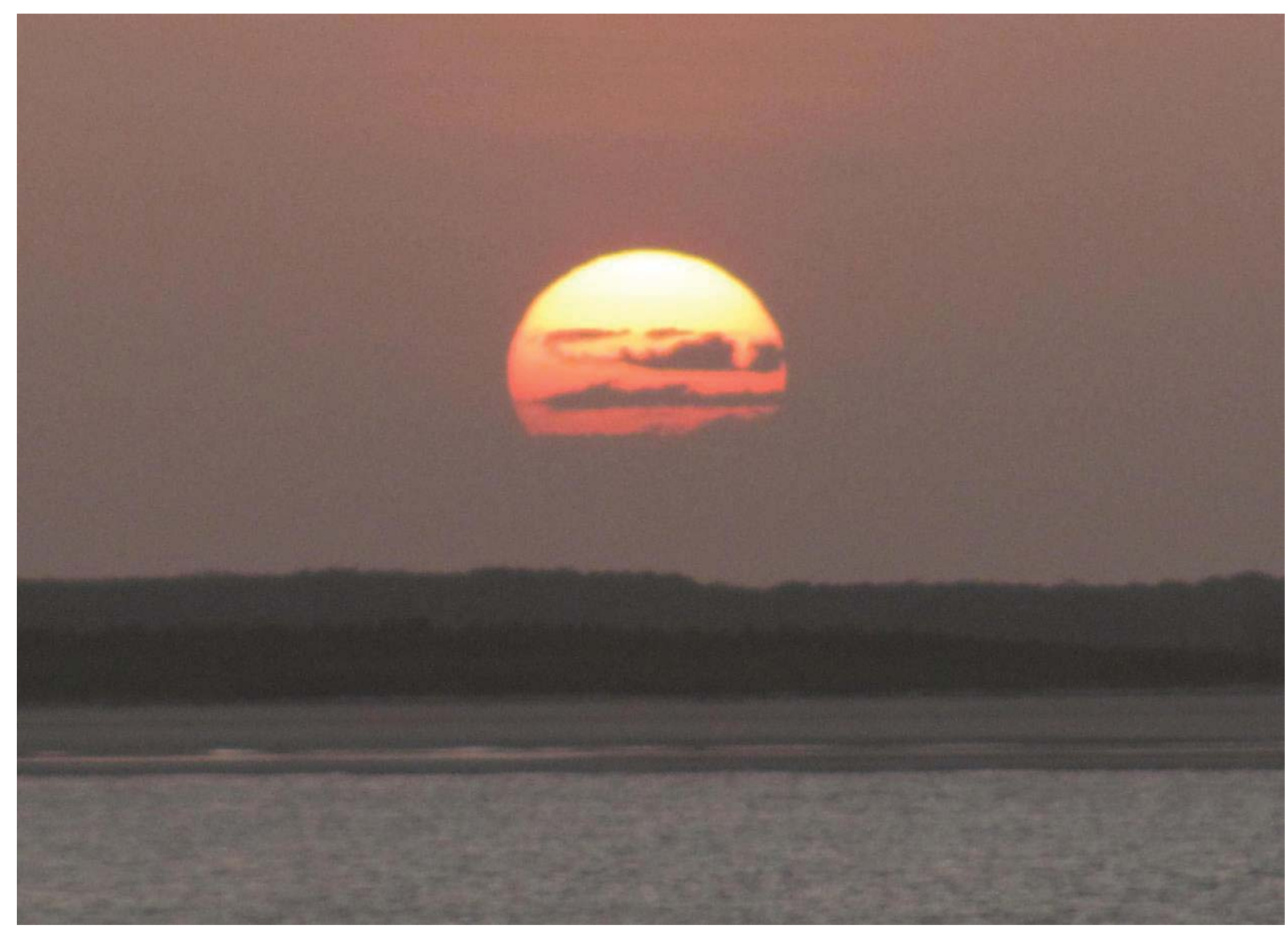

